\title{
Xenopus laevis is a potential alternative model animal species to study reproductive toxicity of phytoestrogens
}

\author{
Lin Cong $^{\mathrm{a}, \mathrm{b}}$, Zhan-Fen Qin ${ }^{\mathrm{a}, *}$, Xiang-Ning Jing ${ }^{\mathrm{b}}$, Lei Yang ${ }^{\mathrm{a}, \mathrm{b}}$, \\ Jing-Ming Zhou ${ }^{\text {a }}$, Xiao-Bai Xu ${ }^{\text {a }}$ \\ ${ }^{a}$ The State Key Laboratory of Environmental Chemistry and Ecotoxicology, Research Center for Eco-Enviromental Sciences, \\ The Chinese Academy of Sciences, Beijing, China \\ ${ }^{\mathrm{b}}$ Beijing Forestry University, Beijing, China
}

Received 26 February 2005; received in revised form 5 December 2005; accepted 5 December 2005

\begin{abstract}
This study investigated effects of phytoestrogen quercetin on the gonadal development in Xenopus laevis. X. laevis at Nieuwkoop and Faber stage 46/47 were exposed to 50, 100 and $200 \mu \mathrm{g} / \mathrm{L}$ quercetin till 1 month postmetamorphosis. Gonads from frogs at 1 and 3 months postmetamorphosis were examined in gross morphology and histology. The highest dose of quercetin as well as estradiol $\left(\mathrm{E}_{2}\right)$ significantly increased the percentages of phenotypic females. Exposure to quercetin at all doses induced abnormal testes with certain ovarian characteristics to some degree in gross morphology, including ovotestes. The abnormality rate exceeded $10 \%$ in each quercetin treatment. Histologic examination revealed that some abnormal testes exhibited intersexuality with testicular structure and ovarian structure or oocytes interspersed in testicular structure at 1 month postmetamorphosis. At 3 months postmetamorphosis, testicular abnormalities were more obvious, such as necrosis or apoptosis of spermatogonia, occurrence of developed or undeveloped oocytes, delay of the development of seminiferous tubes without or less late stage spermatocytes. The results have shown that quercetin cannot only feminize but also impair testicular development of $X$. laevis, i.e. $X$. laevis is sensitive to phytoestrogen. It is suggested that $X$. laevis might be an alternative model species to study reproductive toxicity of phytoestrogens.
\end{abstract}

(C) 2006 Elsevier B.V. All rights reserved.

Keywords: Xenopus laevis; Reproductive toxicity; Phytoestrogen; Quercetin; Feminization

\section{Introduction}

Phytoestrogens are plant-derived components with estrogenlike structure and activities (Setchell, 1998; Adlercreutz, 2002). Since phytoestrogens in alfalfa and clovers were found to affect the fertility of sheep about 50 years ago (Bennetts et al., 1946), reproductive toxicity of phytoestrogens as a kind of endocrine disruptor has aroused considerable attention. A myriad of experimental studies were performed to explore effects of phytoestrogens on the structures and functions of the reproductive system and related mechanisms. To date, there is evidence that phytoestrogens (such as genistein, coumestrol, quercetin), given in high doses or at critical stages of development in experi-

\footnotetext{
* Corresponding author at: P.O. Box 2871, Research Center for Eco-Environmental Sciences, The Chinese Academy of Sciences, Beijing 100085, China. Tel.: +8610 62919177; fax: +861062923563.

E-mail address: zhfqin@yahoo.com (Z.-F. Qin).
}

mental animals can result in severe reproductive tract disorders (Lamartiniere et al., 1995; Strauss et al., 1998; Tou et al., 1999), and temporary infertility syndromes in domestic animals have been related to high phytoestrogens consumption in grazing (Adams, 1995).

Most of the current understanding of reproductive toxicity of phytoestrogens is based on studies in rodent model system, especially in rats. Rats are conventional model animals for reproductive biology and endocrinology, and they have being used to study toxicity of toxicants. The Endocrine Disruptor Screening and Testing Advisory Committee (EDSTAC) recommended the laboratory rat as the species for screening and testing endocrine disruptors (U.S. EPA, 1998). However, many studies involving endocrine disruptors (including phytoestrogens) with rats lack reproducibility and also show inter-laboratory inconsistencies. In addition to the complexity of the endocrine system, some researchers think that different sensitivities of model animals and variable levels of phytoestrogen in diets should be responsible for the variable results (Everitt and Foster, 2004; Naciff et 
al., 2004; Thigpen et al., 2004). Stokes suggests that it is critical to select appropriate animal models and diets for endocrine disruptor studies (Stokes, 2004). Consequently, we considered whether there is an alterative animal species, whose diets do not contain phytoestrogens, to study reproductive toxicity of phytoestrogens, especially effects on the gonadal development.

Amphibians might represent potential sentinels for assessing adverse effects of environmental factors because of their permeable skins and biphasic life-history strategies (van der Schalie et al., 1999). Xenopus laevis is an amphibian species used widely as a model for developmental biology in laboratory studies. In recent years, $X$. laevis has attracted interest of environmental scientists because of the potential sensitivity to endocrine disruptors. In previous studies, the sensitivity of the gonadal development in X. laevis to estrogens has been demonstrated in vivo and in vitro (Witschi and Allison, 1950; Gallien, 1953; Chang and Witschi, 1956; Miyata and Kubo, 2000). Villalpando and Merchant-Larios reported that $100 \mu \mathrm{g} / \mathrm{L}$ estradiol benzoate induced complete sex-reversal in genetic male $X$. laevis (1990). Miyata et al. treated $X$. laevis with $100 \mu \mathrm{g} / \mathrm{L}$ estradiol $\left(E_{2}\right)$ and obtained $100 \%$ females (1999). There is increasing evidence that endocrine disruptors with estrogenic activities also can induce gonadal feminization in $X$. laevis and affect sexual hormone homeostasis (Kloas et al., 1999; Hayes et al., 2002; Qin et al., 2003; Levy et al., 2004). In our previous study, X. laevis was suggested to be good model animal for assaying endocrine disruptors (Qin et al., 2003). Furthermore, in a pre-experiment on the sensitivity of gonadal development, we found that quercetin might have feminizing effects on the gonadal development of $X$. laevis. Considering the disadvantages of rats as model animals to study phytoestrogens, therefore, we suppose whether $X$. laevis might be used as an alternative species if the gonadal development of $X$. laevis is sensitive to phytoestrogens. In this study we further examined the effects of quercetin, which is a natural flavonol widely distributed in plant diets and which can exert various biological effects, and determined the sensitivity of the gonadal development of $X$. laevis to this phytoestrogen.

\section{Materials and methods}

\subsection{Breeding and housing}

Mature female and male $X$. laevis were maintained separately in glass tanks containing dechlorinated water at $22 \pm 2{ }^{\circ} \mathrm{C}$ with a 12-h light/12-h dark cycle and fed once a week on chopped pork liver. Breeding was induced by injection of human chorionic gonadotrophin. After eggs were laid, the females and the males were taken out of the breeding tank. Fertilized eggs were incubated at $22 \pm 2{ }^{\circ} \mathrm{C}$ with a 12-h light/12-h dark cycle. On day 5 after fertilization, tadpoles were fed on Daphnia and Artemia daily.

\subsection{Exposure to chemicals}

Quercetin (purity 98\%, National Research Center for Certified Reference Materials) and $\mathrm{E}_{2}$ (purity 98\%, Merck) were dissolved in ethanol to produce stock solutions. The experiment water was prepared by adding the stock solution to dechlorinated water. The final concentration of $\mathrm{E}_{2}$ as positive control in water was $100 \mu \mathrm{g} / \mathrm{L}$. Quercetin exposure was performed in three doses, 50, 100 and $200 \mu \mathrm{g} / \mathrm{L}$. The control group received the same amount of ethanol used as solvent for the highest quercetin dose. On day 6 after fertilization, healthy tadpoles at NF stage $46 / 47$ among the offspring of a pair of parental frogs were randomly selected for the exposure experiment (Nieuwkoop and Faber, 1956). Each treatment in duplicate consisted of 30 tadpoles in a glass tank containing $18 \mathrm{~L}$ water. Exposure stopped at 1 month postmetamorphosis. All tanks were the same in size and shape $(30 \mathrm{~cm} \times 20 \mathrm{~cm} \times 25 \mathrm{~cm})$. The experiment water was renewed twice weekly.

\subsection{Gonadal identification and histologic examination}

The survival rate of each group was examined at 1 month postmetamorphosis, and approximately two thirds of frogs were sacrificed to determine the sex. One third of frogs was maintained to 3 month postmetamorphosis and examined. The sex ratios in each group were measured based all examined frogs. The sex of all individuals was determined based on gross gonadal morphology using a dissecting microscope. Normal ovaries are characterized by greater length, lobed structure, and melanin granules. Normal testes are characterized by ellipsoid/cylinder, smooth surface, and without melanin granules. In our experiment, frogs with typical ovaries were distinguished as females, while frogs with typical testes were distinguished as normal males. The other frogs that had abnormal testes with certain ovarian characteristics to some degree were determined to be abnormal males. Histologic analysis was conducted on all abnormal gonads and some normal gonads. Gonads attached to kidneys were fixed with Bouin's fixative, then embedded in paraffin, sectioned at $6 \mu \mathrm{m}$, and stained with hematoxylin and eosin. Sections were examined with a light microscope. All procedures were conducted in accordance with the NIH Guide for the Care and Use of Laboratory Animals (National Research Council, 1996).

\subsection{Statistical methods}

Data were analyzed by using the $t$-test. A value of $\alpha=0.05$ was chosen to detect significant difference.

\section{Results}

The survival rates of 50, 100 and $200 \mu \mathrm{g} / \mathrm{L}$ quercetin-exposed groups were $71.7 \%$ (43/60), 71.7\% (43/60), and 76.7\% (46/60), respectively, while the positive control and the control were $80 \%$ (48/60) and $73.3 \%$ (44/60). The survival rate had no difference among each group. The percentage of females in the $200 \mu \mathrm{g} / \mathrm{L}$ treatment group $(67.4 \%, 31 / 46)$ as well as that in the positive control group $(83.3 \%, 40 / 48)$ was significantly higher than in the control $(48.8 \%, 20 / 41)$, while there was no significant difference between the 50 or $100 \mu \mathrm{g} / \mathrm{L}$ quercetin-exposed groups $(55.3 \%, 21 / 38 ; 60 \%, 24 / 40)$ and the control (Fig. 1). Ovotestes occurred among $E_{2}$-exposed individuals (16.7\%). Exposure of 


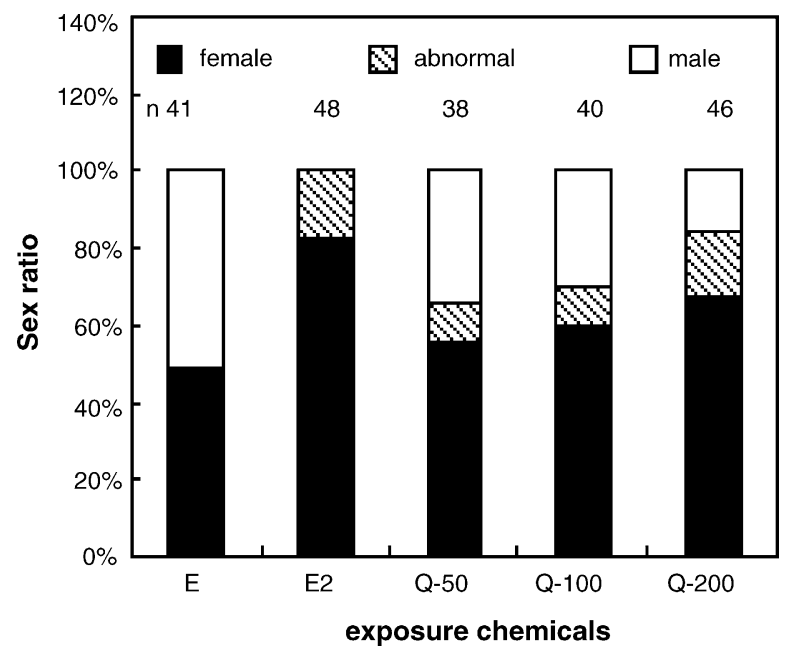

Fig. 1. Sexual percentages based on gonadal examination using microscope in quercetin treatments compared with the control (E) and the positive control $\left(E_{2}\right)$. The percentages of females in $200 \mu \mathrm{g} / \mathrm{L}$ treatment as well as that in $E_{2}$ was significantly higher compared to the control, while it had no significant difference between 50 and $100 \mu \mathrm{g} / \mathrm{L}$ treatments with the control $(p<0.05)$.

quercetin at all doses induced abnormal testes with certain ovarian characteristics to some degree in gross morphology, including ovotestes (Fig. 2). The abnormality rate exceeded $10 \%$ in each quercetin treatment with no obvious abnormality in the control. The results indicate that quercetin has induced feminization of $X$. laevis. Histologic examination revealed that some abnormal testes exhibited inter-sexuality with testicular structure and ovarian structure or oocytes interspersed in testicular structure at 1 month postmetamorphosis (Fig. 3). At 3 months postmetamorphosis, normal testes consist of well-developed seminiferous tubes with multi-stages spermatocysts and spermatozoa. At least five testes were histologically examined in each group, and all showed varying degrees of testicular abnormalities such as necrosis or apoptosis of spermatogonia, occurrence of developed or undeveloped oocytes, or delay of the development of seminiferous tubes without or less late stage spermatocytes (Fig. 4). The histologic results have shown that quercetin cannot only feminize but also impair testicular development of $X$. laevis.

\section{Discussion}

Gonadal differentiation in amphibians corresponds to their genetic sex constitution (Hayes, 1998). Natural intersexuality exists among some juvenile amphibians, but it does not occur in X. laevis (Gallien, 1974). However, estrogen-treatment during embryonic development in $X$. laevis can produce gonadal sex-reversal in genetic males (Gallien, 1953; Villalpando and Merchant-Larios, 1990). In 1999, Kloas et al. reported that bisphenol A and 4-nonylphenol caused a significantly higher number of female phenotypes compared to control X. laevis, which is the first evidence that endocrine disruptor can induce feminization in X. laevis (1999). Since then, there has been increasing data on feminizing effects of endocrine disruptors on $X$. laevis, such as atrazine, polychlorinated biphenyls and bisphenol A (Hayes et al., 2002; Qin et al., 2003; Levy et al., 2004) despite contrary results reported as well (Pickford et al., 2003; Carr et al., 2003). In this study, we for the first time report that the phytoestrogen quercetin also has influence on the gonadal developemt in X. laevis. The sex ratio towards females has shown that quercetin has feminizing effect on genetic male $X$. laevis. Histologic intersexuality has further demonstrated feminizing effect of quercetin. Undevelopmental seminiferous tubes with early stage spermatocytes and necrosis or apoptosis of spermatogonia
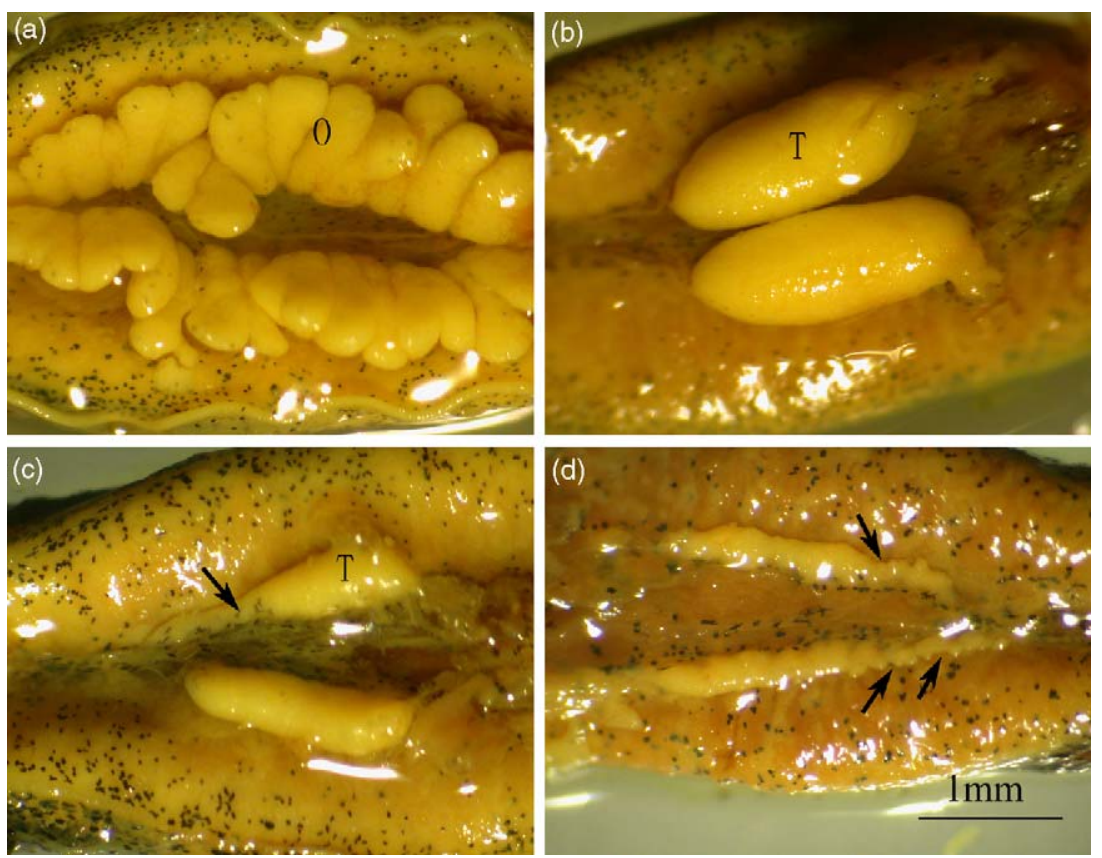

Fig. 2. Abnormal testes induced by quercetin compared with control gonads. (a) Control ovaries (O) distinguished by greater length, lobed structure, and melanin granules. (b) Control testes (T) distinguished by ellipsoid/cylinder, smooth surface, and no melanin granules. (c-d) Abnormal testes caused by quercetin. (c) There were melanin granules and goffer in the end of testis (arrow). (d) Constrictions (arrow) occurred in some sites so that testes tended to be divided into lobed structures. 

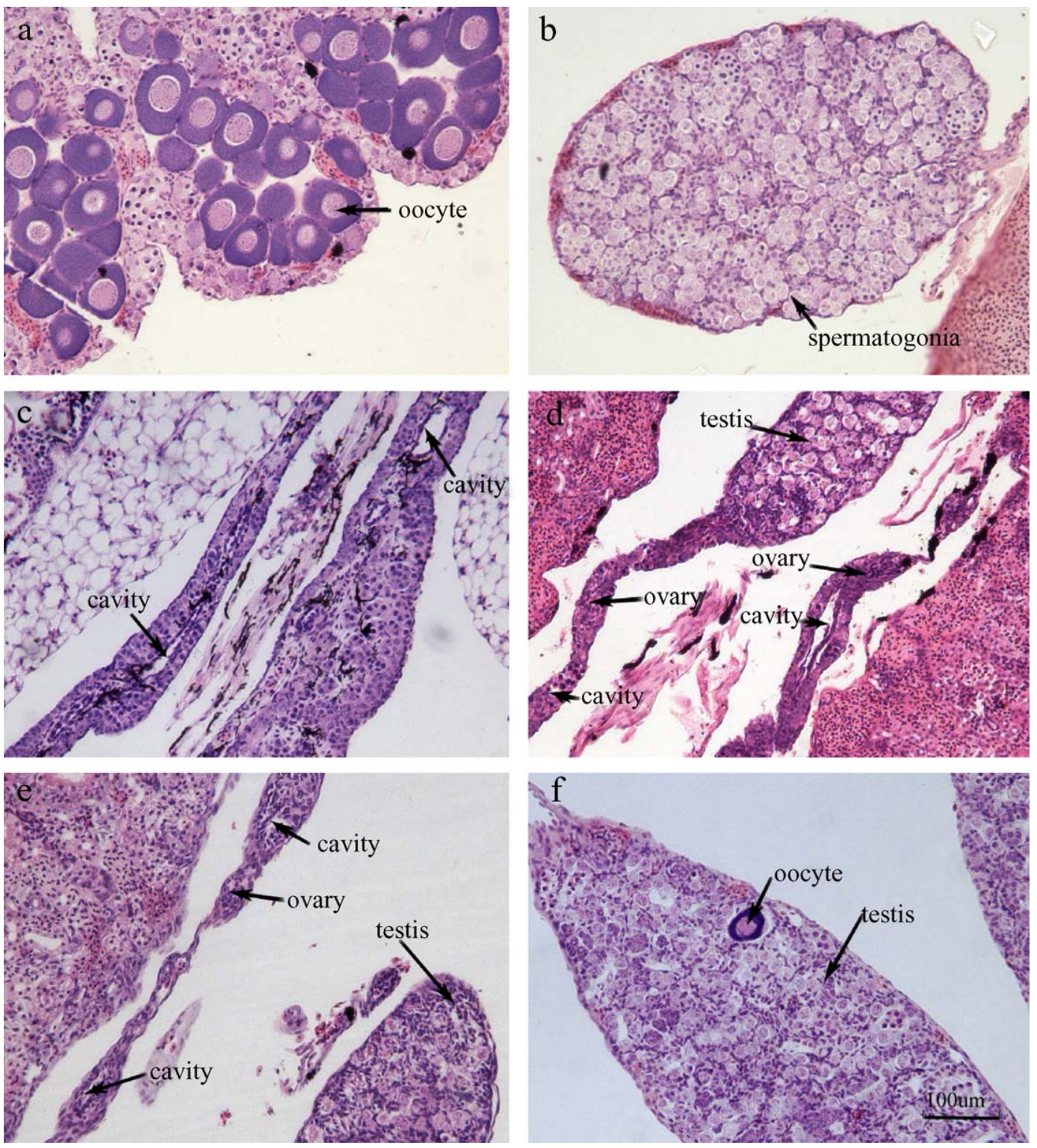

Fig. 3. Photomicrographs of gonadal sections from frogs at 1 month postmorphosis except for (c). (a) Normal ovarian tissue with numerous oocytes. (b) Normal testicular tissue with numerous spermatogonia. (c) Normal ovarian tissue from a tadpole at stage 58. Cavities occur in the medullary region in the process of ovarian development. (d) Intersexuality induced by $E_{2}$. Testicular structure and ovarian structure exist in a gonad. (e-f) Intersexuality induced by quercetin. Testicular structure and ovarian structure exist in a pair of gonads, or oocytes are interspersed in testicular structure.

have indicated that quercetin cannot only feminize but also impair testicular development.

Quercetin can exert various biological effects, including anticarcinogenic, antioxidant and (anti-) estrogenic effects, and modulation of sex hormone homeostasis (Schmitt and Stopper, 2001). Estrogenic and anti-estrogenic effects of phytoestrogens involving sex determination are complex and controversial. In this study, quercetin exhibited estrogenic effects on gonadal development in X. laevis. The mechanism of feminizing effects of quercetin has been unknown despite several studies suggesting that quercetin possibly exerts (anti-) estrogenic effects through modulation of sex hormone homeostasis by affecting aromatase, a key enzyme in the synthesis of estrogens from androgens (Campbell and Kurzer, 1993; Papiez et al., 2002; Sanderson et al., 2004).
In past decades, most studies showed that phytoestrogens given in high dose or at critical stages of development in rodents can result in severe reproductive system disorders, such as inhibition of LH secretion, decrease of plasma testosterone concentrations and prostate weight (Wanichacheewa et al., 2001; Wisniewski et al., 2003; Opalka et al., 2004). Simultaneously, some authors reported that there are no significant effects of phytoestrogens in rodents (Roberts et al., 2000; Mitchell et al., 2001; Lamartiniere et al., 2002). One of the explanations for these inconsistent results is that commercial rodent diets all contain high and variable levels of abundant phytoestrogens, which could affect results of studies on reproductive toxicity of test phytoestrogens (Odum et al., 2001; Stroheker et al., 2003; Naciff et al., 2004; Thigpen et al., 2004). In this study, X. laevis tadpoles were fed Daphnia and Artemia, and frogs were 

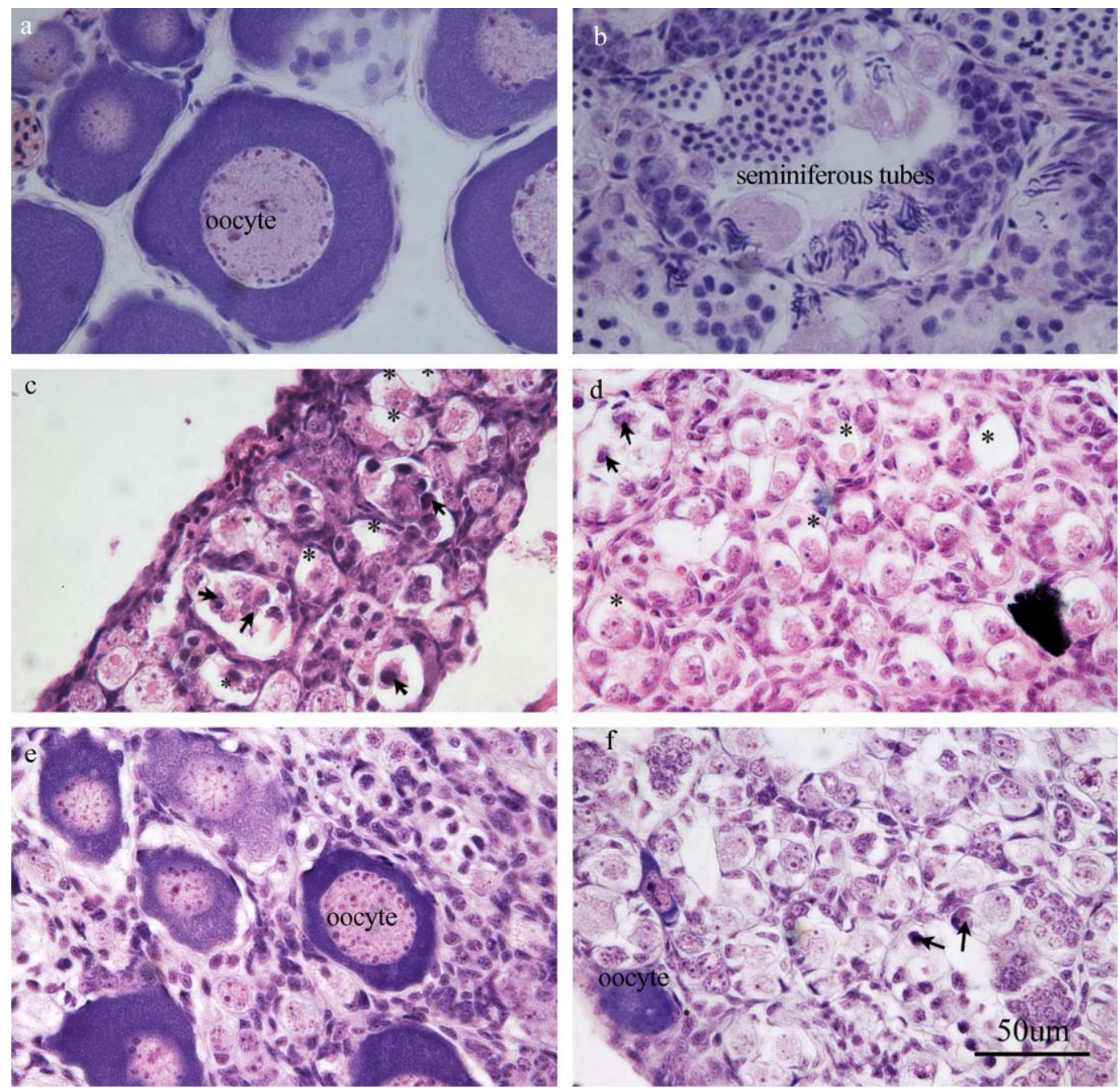

Fig. 4. Photomicrographs of gonadal sections from frogs at 3 month postmorphosis except for (c). (a) Normal ovarian tissue with numerous oocytes. (b) Normal testicular tissue with well-developed seminiferous tubes with multi-stages of spermatocysts and spermatozoa. (c) Testicular tissue from a frog exposed $\mathrm{E}_{2}$. Some spermatogonia seem to be necrotizing or apoptosing (*). Some spermatogonia have the appearance of oocytes (arrows). (d) Testicular tissue from a frog exposed quercetin. It exhibits the same abnormality as (c). (e-f) Intersexuality induced by quercetin. Oocytes are interspersed in testicular structure. There are not welldeveloped seminiferous tubes. There are more early spermatocytes and less late spermatocytes.

fed pork liver. These diets do not contain phytoestrogens, and did not contain some endocrine disruptors such as DDT, polychlorinated biphenyls (unpublished data). Thus, the studies on phytoestrogens using $X$. laevis as a model animal species can avoid the confounding effect of phytoestrogens in the diet.

Recently, several research groups used fish to study reproductive toxicity of phytoestrogens. Zhang et al. reported that genistein increased the estradiol production of ovaries and decreased testosterone production from ex vivo testis and a comparable reduction in circulating testosterone level in Japanese medaka (Zhang et al., 2002). The phytoestrogen beta-sitosterol was reported to alter the reproductive endocrine status of goldfish (MacLatchy and Van Der Kraak, 1995). These studies showed that fish are sensitive species for assaying reproductive toxicities of phytoestrogens. However, there is no evidence that phytoestrogen can induce intersexuality or sex reversal in fish.

In this report, feminizing effects of low dose quercetinexposure, including intersexuality, were observed at 3 months postmetamorphosis. In the rodent model, reproductive toxicity of phytoestrogens can be found generally at ppm dose levels (Awoniyi et al., 1998; Weber et al., 2001). However, intersexuality like that induced by quercetin in $X$. laevis has not been reported in rodents. In other words, X. laevis might be more sensitive to phytoestrogens than rodents. In a previous study, we have suggested that $X$. laevis, a well-developed animal model for developmental biology, might be an alternative animal model for studying endocrine disruptors because of their sensitivity to endocrine effects and a rich literature on reproduction and development (Qin et al., 2003). The sensitivity of X. laevis to endocrine disruptors has attracted attention (Kloas, 2002; Klann et al., 2005), and increasingly, researchers are beginning to use $X$. laevis to study endocrine disruptors (Hayes et al., 2002; Pickford and Morris, 2003; van Wyk et al., 2003). Based on our results, here, we suggest $X$. laevis might be alternative model animal to study reproductive toxicity of phytoestrogens involving endocrine disruption. Our study also responds 
to the proposal of EDSTAC that amphibian development and reproduction are promising endpoints for evaluating endocrine disruptors (U.S. EPA, 1998). In conclusion, this study revealed feminizing effects of phytoestrogen quercetin on the gonadal development in $X$. laevis, and suggests that $X$. laevis might be a useful alternative model species to study reproductive toxicity of phytoestrogens.

\section{Acknowledgements}

This work was supported by grants from the National Science Foundation of China (20377044 and 20437020), the Knowledge Innovation Program of Chinese Academy of Sciences (KZCX2414), the 863 Plan of Ministry of Science and technology of the People's Republic of China (2003AA646010).

\section{References}

Adams, N.R., 1995. Organizational and activational effects of phytoestrogens on the reproductive tract of the ewe. Proc. Soc. Exp. Biol. Med. 208, 87-91.

Adlercreutz, H., 2002. Phyto-oestrogens and cancer. Lancet Oncol. 3, 364-373.

Awoniyi, C.A., Roberts, D., Veeramachaneni, D.N., Hurst, B.S., Tucker, K.E., Schlaff, W.D., 1998. Reproductive sequelae in female rats after in utero and neonatal exposure to the phytoestrogen genistein. Fertil. Steril. 70, 440-447.

Bennetts, H.W., Underwood, E.T., Shier, F.C., 1946. A specific breeding problem of sheep on subterranean clover pastures in Western Australia. Aust. Vet. J. 22, 2-12.

Campbell, D.R., Kurzer, M.S., 1993. Flavonoid inhibition of aromatase enzyme activity in human preadipocytes. J. Steroid. Biochem. Mol. Biol. 46, 381-388.

Carr, J.A., Gentles, A., Smith, E.E., Goleman, W.L., Urquidi, L.J., Thuett, K., Kendall, R.J., Giesy, J.P., Gross, T.S., Solomon, K.R., Van Der Kraak, G., 2003. Response of larval Xenopus laevis to atrazine: assessment of growth, metamorphosis, and gonadal and laryngeal morphology. Environ. Toxicol. Chem. 22, 396-405.

Chang, C.Y., Witschi, E., 1956. Genetic control and hormonal reversal of sex differentiation in Xenopus. Proc. Soc. Exp. Biol. Med. 93, 140-144.

Everitt, J.I., Foster, P.M.D., 2004. Laboratory animal science issues in the design and conduct of studies with endocrine-active compounds. ILAR J. $45,417-424$.

Gallien, L., 1953. Inversion totale du sexe chez Xenopus laevis Daudin à la suite d' un traitement gynog è ne par le benzoate d' oestradiol administr é pendant la vie larvaire. C. R. S é ances Acad. Sci. (Pris) 273, 1565-1566.

Gallien, L., 1974. In: Loft, B. (Ed.), Intersexuality. Physiology of the Amphibia, vol. II. Academic Press, New York and London, pp. 523-527.

Hayes, T.B., Collins, A., Lee, M., Mendoza, M., Noriega, N., Stuart, A.A., Vonk, A., 2002. Hermaphroditic, demasculinize frogs after exposure to the herbicide atrazine at low ecologically relevant doses. Proc. Natl. Acad. Sci. U.S.A. 99, 5476-5480.

Hayes, T.B., 1998. Sex determination and primary sex differentiation in amphibians: genetic and developmental mechanism. J. Exp. Zool. 281, 373-399.

Klann, A., Levy, G., Lutz, I., Müller, C., Kloas, W., Hildebrandt, J.P., 2005. Estrogen-like effects of ultraviolet screen 3-(4-methylbenzylidene)camphor (Eusolex 6300) on cell proliferation and gene induction in mammalian and amphibian cells. Environ. Res. 97, 274-281.

Kloas, W., 2002. Amphibians as a model for the study of endocrine disruptors. Int. Rev. Cytol. 216, 1-57.

Kloas, W., Lutz, I., Einspanier, R., 1999. Amphibians as a model to study endocrine disruptors. II. Estrogenic activity of environmental chemicals in vitro and in vivo. Sci. Total. Environ. 225, 59-68.
Lamartiniere, C.A., Moore, J., Holland, M., Barnes, S., 1995. Neonatal genistein chemoprevents mammary cancer. Proc. Soc. Exp. Biol. Med 208, $120-123$.

Lamartiniere, C.A., Wang, J., Smith-Johnson, M., Eltoum, I.E., 2002. Daidzein: bioavailability, potential for reproductive toxicity, and breast cancer chemoprevention in female rats. Toxicol. Sci. 65, 228-238.

Levy, G., Lutz, I., Kruger, A., Kloas, W., 2004. Bisphenol A induces feminization in Xenopus laevis tadpoles. Environ. Res. 94, 102-111.

MacLatchy, D.L., Van Der Kraak, G.J., 1995. The phytoestrogen betasitosterol alters the reproductive endocrine status of goldfish. Toxicol. Appl. Pharmacol. 134, 305-312.

Mitchell, J.H., Cawood, E., Kinniburgh, D., Provan, A., Collins, A.R., Irvine, D.S., 2001. Effect of a phytoestrogen food supplement on reproductive health in normal males. Clin. Sci. (Lond). 100, 613-618.

Miyata, S., Koike, S., Kubo, T., 1999. Hormonal reversal and the genetic control of sex differentiation in Xenopus. Zool. Sci. 16, 335-340.

Miyata, S., Kubo, T., 2000. In vitro effects of estradiol and aromatase inhibitor treatment on sex differentiation in Xenopus laevis gonads. Gen. Comp. Endocrinol. 119, 105-110

Naciff, J.M., Overmann, G.J., Torontali, S.M., Carr, G.J., Tiesman, J.P., Daston, G.P., 2004. Impact of the phytoestrogen content of laboratory animal feed on the gene expression profile of the reproductive system in the immature female rat. Environ. Health Perspect. 112, 1519-1526.

National Research Council, 1996. NIH Guide for the Care and Use of Laboratory Animals. National Academy Press, Washington, DC.

Nieuwkoop, P.D., Faber, J., 1956. Normal Table of Xenopus laevis (Daudin). Amsterdam, North-Holland.

Odum, J., Tinwell, H., Jones, K., Van Miller, J.P., Joiner, R.L., Tobin, G., Kawasaki, H., Deghenghi, R., Ashby, J., 2001. Effect of rodent diets on the sexual development of the rat. Toxicol. Sci. 61, 115-127.

Opalka, M., Kaminska, B., Ciereszko, R., Dusza, L., 2004. Genistein affects testosterone secretion by Leydig cells in roosters (Gallus gallus domesticus). Reprod. Biol. 4, 185-193.

Papiez, M., Gancarczyk, M., Bilinska, B., 2002. The compounds from the hollyhock extract (Althaea rosea Cav. var. nigra) affect the aromatization in rat testicular cells in vivo and in vitro. Folia. Histochem. Cytobiol. 40, 353-359.

Pickford, D.B., Hetheridge, M.J., Caunter, J.E., Hall, A.T., Hutchinson, T.H., 2003. Assessing chronic toxicity of bisphenol A to larvae of the African clawed frog (Xenopus laevis) in a flow-through exposure system. Chemosphere 53, 223-235.

Pickford, D.B., Morris, I.D., 2003. Inhibition of gonadotropin-induced oviposition and ovarian steroidogenesis in the African clawed frog (Xenopus laevis) by the pesticide methoxychlor. Aquat. Toxicol. 62, 179-194.

Qin, Z.F., Zhou, J.M., Chu, S.G., Xu, X.B., 2003. Effects of Chinese domestic polychlorinated biphenyls (PCBs) on gonadal differentiation in Xenopus laevis. Environ. Health Perspect. 111, 553-556.

Roberts, D., Veeramachaneni, D.N., Schlaff, W.D., Awoniyi, C.A., 2000. Effects of chronic dietary exposure to genistein, a phytoestrogen, during various stages of development on reproductive hormones and spermatogenesis in rats. Endocrine 13, 281-286.

Sanderson, J.T., Hordijk, J., Denison, M.S., Springsteel, M.F., Nantz, M.H., van den Berg, M., 2004. Induction and inhibition of aromatase (CYP19) activity by natural and synthetic flavonoid compounds in H295R human adrenocortical carcinoma cells. Toxicol. Sci. 82, 70-79.

Schmitt, E., Stopper, H., 2001. Estrogenic activity of naturally occurring anthocyanidins. Nutr. Cancer 41, 145-149.

Setchell, K.D., 1998. Phytoestrogens: the biochemistry, physiology, and implications for human health of soy isoflavones. Am. J. Clin. Nutr. 68 (Suppl. 6), 1333s-1346s.

Stokes, W.S., 2004. Selecting appropriate animal models and experimental designs for endocrine disruptor research and testing studies. ILAR J. 45, 387-393.

Strauss, L., Makela, S., Joshi, S., Huhtaniemi, I., Santti, R., 1998. Genistein exerts estrogen-like effects in male mouse reproductive tract. Mol. Cell. Endocrinol. 144, 83-93.

Stroheker, T., Cabaton, N., Berges, R., Lamothe, V., Lhuguenot, J.C., Chagnon, M.C., 2003. Influence of dietary soy isoflavones on the acces- 
sory sex organs of the Wistar rat. Food Chem. Toxicol. 41, 11751183.

Thigpen, J.E., Setchell, K.D., Saunders, H.E., Haseman, J.K., Grant, M.G., Forsythe, D.B., 2004. Selecting the appropriate rodent diet for endocrine disruptor research and testing studies. ILAR J. 45, 401-416.

Tou, J.C.L., Chen, J., Thompson, L.U., 1999. Dose, timing, and duration of flaxseed exposure affect reproductive indices and sex hormone levels in rats. J. Toxicol. Environ. Health A 56, 555-570.

U.S. EPA, 1998. Endocrine Disruptor Screening and Testing Advisory Committee (EDSTAC): Final Report. U.S. Environmental Protection Agency, Washington, DC

van der Schalie, W.H., Gardner Jr., H.S., Bantle, J.A., De Rosa, C.T., Finch, R.A., Reif, J.S., Reuter, R.H., Backer, L.C., Burger, J., Folmar, L.C., Stokes, W.S., 1999. Animals as sentinels of human health hazards of environmental chemicals. Environ. Health Perspect. 107, 309-315.

van Wyk, J.H., Pool, E.J., Leslie, A.J., 2003. The effects of anti-androgenic and estrogenic disrupting contaminants on breeding gland (nuptial pad) morphology, plasma testosterone levels, and plasma vitellogenin levels in male Xenopus laevis (African clawed frog). Arch. Environ. Contam. Toxicol. 44, 247-256.
Villalpando, I., Merchant-Larios, H., 1990. Determination of the sensitive stages for gonadal sex-reversal in Xenopus laevis tadpoles. Int. J. Dev. Biol. 34, 281-285.

Wanichacheewa, S., Singtripop, T., Sassa, S., Sakamoto, S., Mori, T., 2001. Decrease in the number of sperm associated with decreased blood testosterone levels in male rats treated with extracts from seven plants consumed by natives of northern Thailand. Environ. Toxicol. Pharmacol. 10, 1-4.

Weber, K.S., Setchell, K.D., Stocco, D.M., Lephart, E.D., 2001. Dietary soy-phytoestrogens decrease testosterone levels and prostate weight without altering $\mathrm{LH}$, prostate 5alpha-reductase or testicular steroidogenic acute regulatory peptide levels in adult male Sprague-Dawley rats. J. Endocrinol. 170, 591-599.

Wisniewski, A.B., Klein, S.L., Lakshmanan, Y., Gearhart, J.P., 2003. Exposure to genistein during gestation and lactation demasculinizes the reproductive system in rats. J. Urol. 169, 1582-1586.

Witschi, E., Allison, J., 1950. Responses of Xenopus and Alytes to the administration of some steroid hormones. Anat. Rec. 108, 589-590.

Zhang, L., Khan, I.A., Foran, C.M., 2002. Characterization of the estrogenic response to genistein in Japanese medaka (Oryzias latipes). Comp. Biochem. Physiol. C. Toxicol. Pharmacol. 132, 203-211. 